\title{
Lucas Alamán: un hombre en una época de transición
}

Guillermina del Valle Pavón

INSTITUTO MOR A

INTRODUCCIÓN

$\mathrm{E}$ ntre los políticos e intelectuales de las primeras décadas del Méxjco independiente destaca Lucas Alamán, quien además promovió importantes proyectos de carácter económico. Su época fue escenario de grandes conmociones provocadas por el tránsito del régimen colonial-corporativo al soberano, republicano y liberal; mientras que en casi toda Europa se vivía la Restauración, después del fracaso del terror revolucionario jacobino y del militarismo imperial napoleónico.

Las concepciones historiográficas dominantes -la historia oficial entre otras- han tenido a Lucas Alamán co- mo uno de los principales enemigos de la nación por sus críticas a los excesos de la revolución insurgente, su oposición a las "prácticas democráticas" tendientes a implantar el sufragio universal, su antagonismo al federalismo disgregador de la época, y su defensa de las instituciones corporativas como el municipio, el ejército y la Iglesia, consideradas como prolongaciones del régimen colonial.

Las críticas a la figura histórica de Alamán tienen su origen en una concepción tradicionalista que concibe a la historia política de las primeras décadas de vida independiente como una lucha entre "liberales" y "conservadores". Tal esquema ideológico carece de objetividad y oculta los puntos de 
coincidencia entre quienes representaban ambas tendencias. Se ha negado reconocimiento a la obra de Lucas Alamán porque ha sido juzgada a la luz de los valores del liberalismo doctrinario y del nacionalismo revolucionario, enfoques que han distorsionado la interpretación del pasado con valores presentes y han hecho abstracción de la circunstancia histórica en que vivió Alamán.

Lucas Alamán es un personaje paradigmático cuya biografía enlaza el fin de la vida política novohispana y el principio de la etapa nacional. El estudio de los hombres de su generación nos muestra el esquematismo de la división tajante entre colonia e independencia, ya que el resquebrajamiento del México colonial no fue repentino ni fulminante, sino un difícil proceso de recomposición estructural. En tales circunstancias, Alamán surge como un patriota que buscaba conservar la estabilidad política y el auge económico que caracterizó a México durante las últimas décadas de la época colonial.

A continuación se discuten las principales objeciones que se han hecho a la obra y al pensamiento de Lucas A lamán. Con el apoyo de la historiografia contemporánea, cuyas aportaciones han permitido identificar con mayor claridad a los contendientes políticos de la época posindependiente y a los problemas que los distanciaron, es posible hacer un

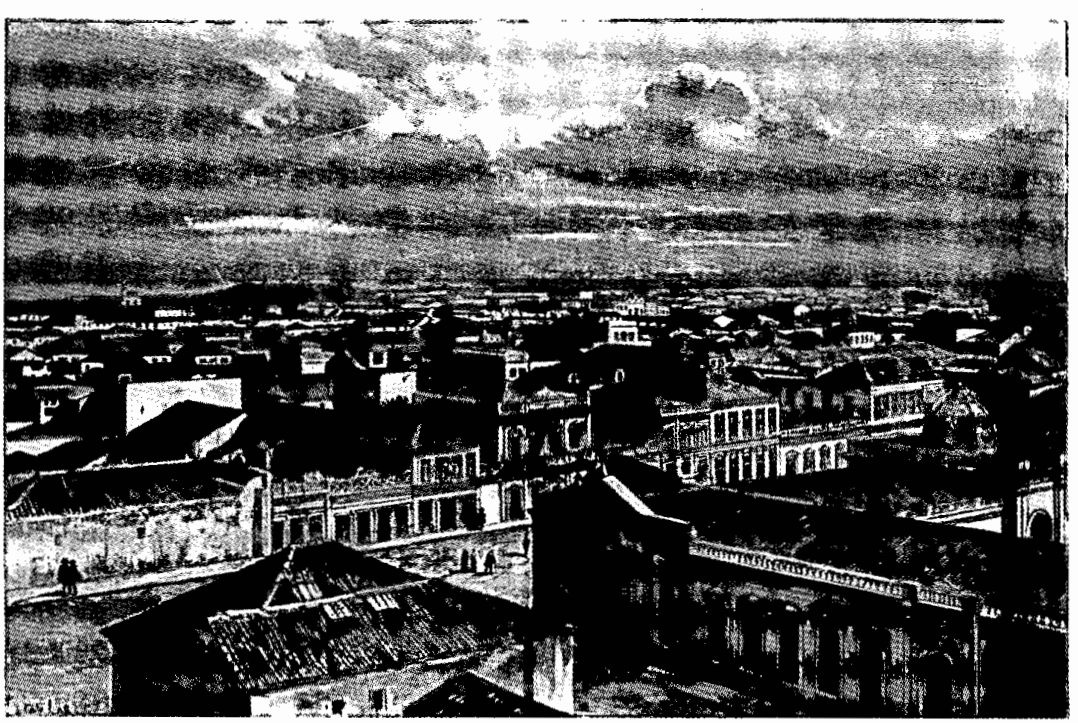


juiciohistórico más equilibrado de este mexicano sobresaliente.

\section{EL AUTONOMISMO CONSTTTUCIONAL Y SU ACTITUD ANTE LA REVOLUCIÓN DE INDEPENDENCIA}

Varios motivos guiaron a Lucas Alamán para dedicar buena parte de sus textos históricos a juzgar de manera crítica los sucesos que giraron en torno a la revolución insurgente. Entre ellos, su repudio a la destrucción que el movimiento ocasionó, su oposición a las propuestas radicales que proclamaron sus líderes ${ }^{1}$ y su interés por reivindjcar la consumación de la independencia como obra del grupo autonomista que en 1821 encabezó Agustín de Iturbide.

La ruina provocada por la revolu. ción de 1810 fue incuestionable. En 1817 el secretario del Real Consulado de Veracruz demost ró que hasta antes de 1810 la economía novohispana producía anualmente una "masa circulante de 227812939 pesos", y cómo ésta padeció "en cada año de revolución un quebranto de más de 131000000 de pesos", elevándose en los primeros siete años de insurrección a 917000000 de pesos, sin que hasta entonces se hubiera logrado la independencia. ${ }^{2}$ En la actualidad se calcula que la produc-

\footnotetext{
1 Entre las demandas de los insurgentes destacan la soberania popular, el reparto de las tierras entre los labradores, la exclusividad de $\mathrm{em}$ pleos para los americanos, la liberación de los esclavos, la abolición de la distinción de castas, la confiscación de los bienes de los europeos y la supresión de tributos, parte de las cuales se con. siguieron hasta después de la revolución de 1910.
}

2 Quirós, "Memoria", 1943, pp. 119, 123. ción promedio anual de plata de las dos décadas anteriores a 1810 fue de 24000000 , en tanto que la de 1811 a 1830 no superó los 13000000 de pesos anuales a consecuencia de la devastación causada por la guerra. ${ }^{3}$

Los trastornos sobre la economía novohispana se evidenciaron a los pocos meses de haberse iniciado la revolución. En 1812 el obispo de Michoacán, Manuel Abad y Queipo, emitió en su diócesis un edicto para dividir entre deudores y acreedores los daños causados por la "extensión, universalidad y rapidez" con que se habían extendido los estragos de la insurrección. Con ello pretendía evitar que a la guerra civil siguiera una "guerra forense" originada por las ejecuciones de los juicios realizados por el incumplimiento generalizado de los contratos de crédito. ${ }^{4}$ En 1819, Fernando VII tuvo que hacer extensivas a toda Nueva España dichas disposiciones al ordenar la creación de una ley que conciliara los intereses crediticios mediante la baja de réditos y la supresión de los embargos por adeudos, entre otras medidas. ${ }^{5}$

La mayor parte de los historiadores contemporáneos a Lucas Alamán re. probaron los estragos ocasionados

3 Schneider, Minería, 1980, p. 246.

4 Abad y Queipo fundamentaba su iniciativa en la forma en que la revolución insurgente "obstruyó todo el giro de la sociedad desde Veracruz a Sonora, y desde Acapulco al Nuevo México. Degolló a sangre fría una gran porción de ciudadanos de los más iníeresantes y preciosos. Arruinó las rentas del soberano y de la Iglesia, y los capitales de comercio y de habilitación de toda industria rústica y urbana." [sic]. Abad y Queipo, "Edicto", 1986, p. 158.

5 Véase Jáuregui, Discurso, 1820. 
por los insurgentes y cuestionaron a sus líderes, sin que por ello hayan sido estigmatizados como adversarios o antipatriotas. José María Luis Mora, considerado "el vocero liberal más sobresaliente de su generación" y cuyo mérito se reconoce hasta nuestros días, ${ }^{6}$ juzgó acremente a Miguel Hidalgo por la violencia y el saqueo provocado por la revuelta que encabezó. Mora aseguraba que el iniciador del movimiento de independencia obraba con "ligereza", por lo que "no sabía ni lo que había de hacer al día siguiente, y mucho menos se ocupaba de la clase de gobierno que debería establecerse después del triunfo para regir la nueva nación". ${ }^{7}$ Pensaba que, como consecuencia de la carencia absoluta de programa, el caudillo había hecho descender la revolución

hasta las últimas clases, y radicar en ellas el odio contra los españoles, precipitándose con la velocidad del rayo sobre las principales poblaciones, y desorganizan. do con las masas a que daba impulso, el gobierno que tenía por enemigo y los medios que la cadena de autoridades subordinadas a su obediencia le prestaban para sostenerse o rehacerse. ${ }^{8}$

En busca de los principios políticos que guiaron a Hidalgo en su lucha, Mora analizó su Manifiesto a la nación americana, de donde concluyó que había una "falta absoluta de ellos", ya que

no se anuncia ninguna mejora, ningún principio político, ni aun la indepen-

6 Hale, Liberalismo, 1982, p. 73.

7 Mora, México, 1977, p. 33.

8 Ibid., pp. 33,34 dencia misma; en él se habla de agravios, de padecimientos, sin especificarlos, sin explicar a la multitud en qué consistian, ni el sistema que se podría adoptar para repararlos, evitar que se perpetuasen o reprodujesen en lo sucesivo [...] hay errores, falsedades y máximas antisociales; se anuncia que la religión corre riesgo con los españoles, se procura hacer odiosos a éstos, se promete la exclusión de extranjeros, y se siente como indudable que la revolución ha sido de preferencia provocada y sostenida por motivas religiosos, y que los males públicos cesarán con las exclusiones pronunciadas. 9

Lucas Alamán tuvo especial interés en que se reconociera el mérito de Agustín de Iturbide respecto de la consuma. ción de la independencia. En primer lugar, por apego a la verdad histórica pero, principalmente, por considerar que el programa que propuso en el Plan de Iguala "formaba una transición natural al nuevo orden de cosas". ${ }^{10} \mathrm{En}$ ello coincidió el liberal Lorenzo de Za. vala, quien aseguró sobre dicho plan que "teniendo presentes las circuns. tancias en que se hallaba la nación mexicana $[. .$.$] fue una obra maestra de$ política y de saber". Mientras que de Iturbide y el movimiento que dirigía opinaba que

no era [...] el grito tumultuoso de Dolores en 1810: no eran indios armados de hoces, piedras y hondas los que gritaban confusamente y en desorden: Mueran los gachupines; viva nuestra Señora de Guadalupe. Era un jefe acreditado por su valor, que apoyado en el voto nacional, con tropas disciplinadas, hablaba

9 Ibid., pp. 114, 115. Cursivas nuestras. ${ }^{10}$ Alamán, Historia, vol. 5 , p. 118. 
en nombre de los pueblos, y reclamaba derechos ya demasiado conocidos. ${ }^{11}$

La propuesta de Iturbide generó verdadero consenso por haberse generalizado entre los distintos grupos sociales el deseo de ejercer la soberanía nacional y tener posibilidad de hacerlo sin la amenaza que hasta entonces había representado la revuelta popular, ya que la nueva propuesta garantizaba que todas "las personas y propiedades, serían respetadas y protegidas" ${ }^{12} \mathrm{EI}$ Plan de Iguala recibió inmediata acepta. ción por parte de los representantes del ejército, la oligarquía, ${ }^{13}$ el clero, e incluso los propios insurgentes; también fue apoyado por "liberales" y "conservadores" como José María Luis Mora y el mismo Lucas Alamán, quienes, profesando muchas ideas en común, se unieron bajo el partido monárquico constitucional de José María Fagoaga ${ }^{14}$ De aquí que el ejército de las Tres Garantías triunfara

11 Zavala, Ensayo, 1985, pp. 88, 92.

12 "Plan de la Independencia", 1987, pp. 123. 125.

13 Agustín de Iturbide recibió, además, el financiamiento de un grupo de mercaderes que tenían fuertes intereses en el comercio del Pacifico y formaba parte de las más altas jerarquías del Consulado de comerciantes de la ciudad de México, institución que desde 1808 había sidoel baluarte de la contrarrevolución por la vinculación de sus intereses con el sistema colonial. Alamán, Historia, 1985, vol. 5, pp. 61, 95, 96 . Mier, Historia, 1986, libros v, vi y vil.

14 Según Hale, José Maria Luis Mora propugnó por la instauración de un príncipe borbónico conforme a lo dispuesto por los Tratados de Cór. doba y cita cómo un amigo íntimo de Mora, Bernardo Couto, luego de la muerte del primero escribió "que éste 'propendía fuertemente a la monarquía templada' [como forma de gobierno]". Hale, Liberalismo, 1982, pp. 84, 85 .

en unos cuantos meses, casi sin derramamiento de sangre.

El Plan de Iguala ha sido visto como una reacción conservadora ante las reformas radicales de los liberales españoles de $1820 .^{15}$ Tal concepción es errónea, Iturbide retomó en su plan el programa autonomista que proponía alcanzar la "absoluta independencia" mediante un gobierno constituido por un monarca de la dinastía borbónica, cuyo poder debía ser "templado por una Constitución análoga al país", la cual sería elaborada por las Cortes o Congreso Constituyente mexicano. También establecía que el nuevo gobierno, sostenido por el ejército, garantizaría la exclusividad de la religión católica y la unidad entre mexicanos y españoles, además de retomar algunas demandas sociales como la abolición de la distinción de castas. ${ }^{16} \mathrm{Y}$, una vez consumada la independencia, estableció el libre comercio.

El movimiento autonomista había tenido su primera manifestación revolucionaria en 1808 cuando el cabildo de la ciudad de México, ante la crisis de

15 Sobre el desconocimiento de los hechos que giraron en torno a la consumación de la independencia, Doris Ladd sostiene: "Lo que conocemos de Iguala -la conspiración, el Plan y el gobierno que fue organizado entre septiembre de 1821 y diciembre de 1822 - refleja una apasionada convicción más que una detallada evidencia. Si dicho ardor ha llegado a convertirse en el estilo de historia que ha trabajado para de. sacreditar a aquellos hombres que consuma. ron' la Independencia de México, no es sorprendente, pues sus enemigos destruyeron deliberadamente las pruebas documentales." Iadd, Nobleza, 1984, pp. 184, 185.

16 "Plan de la Independencia", 1987, pp. 123. 125. 


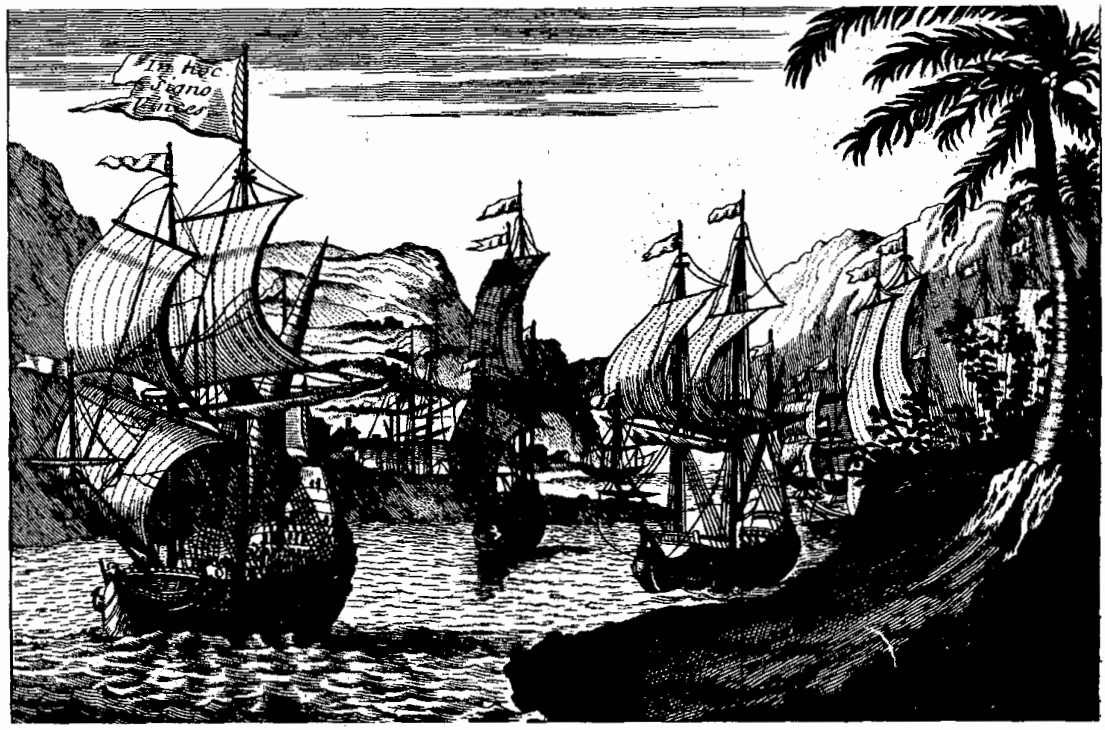

la monarquía española provocada por la invasión napoleónica, pidió a la Real Audiencia convocar a los representantes de las ciudades, corporaciones y tribunales novohispanos para formar una junta de gobierno. ${ }^{17}$ Dicha pro-

17 Alamán no fue el único en reivindicar este hecho como el primer intento de rebeldia novohispana; lo mismo hicieron en su época fray Servando Teresa de Mier, Lorenzo de Zavala y José María Luis Mora. Para este último los eventos de 1808 habían abierto " 'para no cerrarse jamás, la discusión sobre la gran cuestión de la independencia y los derechos político-civiles de los mexicanos' ". Citado en Reyes Heroles, Liberalismo, 1982, p. 10; véase Alamán, Historia, 1985, vol. 1; Mier, Historia, 1986; Zavala, Ensayo, 1985. I a historiografia contemporánea también ha identificado los eventos de 1808 como el inicio de los esfuerzos independentistas novohispanos. Anna, Cafda, 1981, pp. 62, 63, 211; puesta, que reconocía a Nueva España como un ente soberano que formaba parte de la dinastía borbónica sin dependencia ni subordinación a la nación española, fue retomada en 1811 por los representantes de los cabildos novohispanos en el Proyecto de Imperio de estados autónomos, constituido por juntas provinciales que propusieron ante las Cortes de Cádiz. ${ }^{18}$ José María Cos incluyó el mismo planteamiento en el Plan de Paz que los insurgentes presentaron como programa político en $1812 .{ }^{19}$ Y, en 1820, Lucas Alamán,

Annino, "Pacto", 1984, pp. 5, 6; Iadd, Nobleza, 1984, pp. 164, 165; Villoro, "Revolución"n" 1981, pp. $621-623$.

18 Annino, "Pacto", 1984, pp. 6, 7

19 "Plan de Paz", 1987, pp. 107, 108; Villoro, "Historia", 1981, pp. 620, 621. 
Mariano Michelena y Miguel Ramos Arizpe promovieron sin éxito dicha propuesta autonomista ante las Cortes españolas. ${ }^{20}$

En 1821 el movimiento autonomista que entonces encabezó Iturbide había logrado gran aceptación por parte de la oligarquía y la burguesía criolla de México. Estos grupos, luego de haber experimentado el constitucionalismo liberal gaditano de 1812 no podían aceptar nuevamente el absolutismo imperial de Fernando VII ni el liberalismo radical de 1820 , que se negó a concederles sus demandas de autonomía y libre comercio. ${ }^{21}$

Sin embargo, la aversión que causó el establecimiento del imperio de Agustín I y su autoritarismo, unida al predominio que adquirió la interpre. tación insurgente de la guerra de Independencia a raíz del triunfo de la república, provocaron el rechazo de los verdaderos consumadores de la independencia. Ello dio lugar a la sustitución de la fecha de conmemoración de dicho acontecimiento del 27 al 16 de septiembre, y a que Iturbide fuera paulatinamente suprimido de los calenda. rios y discursos cívicos. ${ }^{22}$

Lucas A lamán lamentaba que a Iturbide se le hubiera privado del reconocimiento que le correspondía, mientras a

Hidalgo, Allende, Abasolo [...] se les ha querido atribuir la gloria, si no de haber605.

20 Alamán, Historta, 1985, vol. 5, pp. 591.

21 Anna, Caída, 1981, pp. 201-245. Ladd, Nobleza, pp. 184-201.

22 Arias, México, 1987, pp. 99, 100; Alamán, Historia, vol. 5, pp. 767.769; véase Conciencia, 1988. la hecho a lo menos de haberla intentado y llevado tan adelante que la posterior ejecución de la empresa se ha presentado como una consecuencia de lo que ellos habían adelantado. ${ }^{23}$

Es por ello que, entre la historiografía de su época, la obra de Alamán se distingue por su insistencia en dejar claro que el movimiento que encabezaron los líderes mencionados fue definitivamente derrotado en 1816. A partir de esa fecha únicamente quedaron en la lucha las fuerzas de Vicente Guerrero y Guadalupe Victoria, que resultaban insignificantes desde el punto de vista militar.

\section{SOBERANIA Y REPRESENTACIÓN POLITICA}

Algunos adversarios de Lucas Alamán lo han calificado de "enemigo de la democracia" por su oposición al sufragio universal, hecho que evidencia la falta de conocimiento sobre la discusión del problema y las prácticas electorales que se introdujeron en el México independiente a raíz de la adopción de la Constitución liberal española. El manifiesto rechazo de Alamán a la soberanía popular fue compartido por los principales intelectuales y políticos de la época como reacción a las consecuencias de la revolución insurgente, en la que la participación caótica de las masas había puesto en peligro la seguridad individual.

Fray Servando Teresa de Mier, quien por influencia de la revolución

23 Alamán, Historia, 1985, vol. 2, p. 224. 
francesa se había proclamado jacobino y luego de conocer el levantamiento de Hidalgo había difundido en Londres la idea de la independencia, abandonó su espíritu revolucionario al inicio de la etapa constitucionalista cuando emitió opiniones como la siguiente sobre la democracia popular:

El pueblo siempre ha sido víctima de la seducción de los demagogos turbulentos; y así su voluntad numérica es un fanal muy obscuro, una brújula muy incierta. Lo que ciertamente quiere el pueblo es su bienestar: en esto no cabe equivocación; pero la habría muy grande y perniciosa si se quisiese, para establecer ese bienestar, seguir por norma la voluntad de hombres groseros e ignorantes, cual es la masa general del pue. blo, incapaz de entrar en las discusiones de la política, de la economía y del dere. cho público. ${ }^{24}$

$Y$, al hacer referencia a los principios que reivindicaba la constitución de la nación de acuerdo con la voluntad general, aseveraba: "Principios, si se quiere, metafísicamente verdade. ros; pero inaplicables en la práctica, porque consideran al hombre en abstracto, y tal hombre no existe en la sociedad." 25

En 1822 Francisco Severo Maldonado, erudito sacerdote seguidor de Hidalgo en 1810 y editor de El Despertador Americano - primer periódico revolucionario-, "pugnaba por la

24 Mier, Profecía, 1849, p. 13.

25 lbid., pp. 13-14.

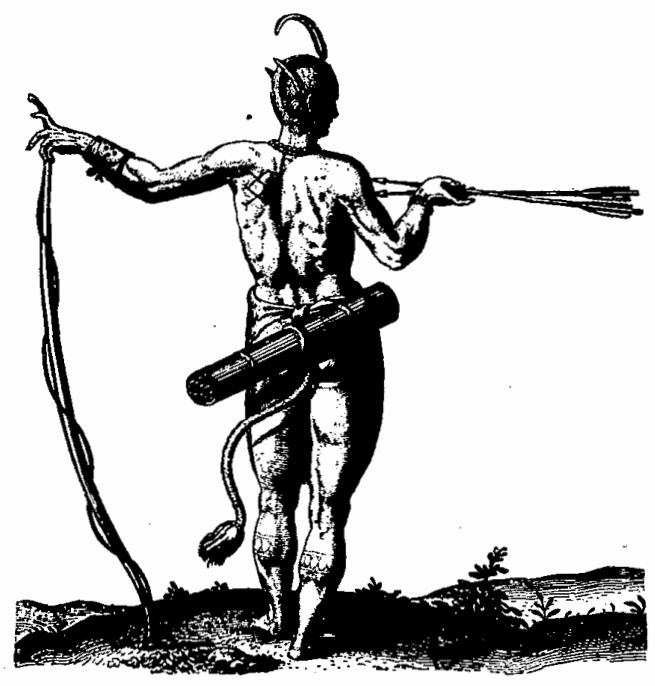


creación de ciudadanos políticamente 'activos' y 'pasivos' con fundamento en la propiedad privada" ${ }^{26} \mathrm{El}$ temor a la participación popular se había acre. centado después del estallido del motín de la Acordada y del saqueo del mercado del Parián -sucesos que evidenciaron el frágil control del gobierno sobre las masas urbanas-;27 así como de la extinción del movimiento popular de Vicente Guerrero que "por un corto tiempo había hecho renacer el gran miedo de una jacquérie parecida a la de Hidalgo". ${ }^{28}$

Unos años después de haber experimentado los trastornos ocasionados por la introducción del sufragio universal, Mora opinaba que "la igualdad mal entendida" condujo a "la escandalosa profusión con que se habían prodigado los derechos políticos, haciéndolos extensivos y comunes hasta las últimas clases de la sociedad". Y consideraba que al permitir la ocupación de los puestos públicos a personas "sin educación ni principios, y cuyo menor defecto ha sido carecer de las disposiciones necesarias para desempeñarlos", se había dado lugar a la invasión del poder arbitrario y la pérdida del respeto por las autoridades. ${ }^{29}$

Entre otros problemas, la elección popular de los cargos de gobierno de

26 Hale, Liberalismo, 1982, pp. 76, 77.

27 Véase Arrom, "Popular", 1988.

28 Annino, "Pacto", 1984, p. 22. Hale sostiene la misma interpretación cuando afirma: "El México criollo, to mismo el liberal que el conservador, se erizó ante la perspectiva de la 'democracia', de la participación activa en política de un Vicente Guerrero, de los indios mayas de Yucatán o de los partidos de Eleuterio Quiroz en la Huasteca". Hale, Liberalismo, 1982, p. 306.

29 Ibid., pp. 630.631. los ayuntamientos dio lugar a que algunos individuos abusaran, en beneficio propio, del desconocimiento general sobre las nuevas prácticas políticas. En 1823 Lucas Alamán puso de manifiesto

el desarreglo que ha solido haber en las elecciones, causado generalmente por la ignorancia de los vecinos poco habituados todavía al sistema, o de la malicia de algunos que han querido volver a su provecho particular un establecimiento que sólo tiene por objeto el bien y la felicidad común. ${ }^{30}$

La manipulación de las elecciones también condujo a Mora a evidenciar la forma en que el sufragio era abando. nado "a la seducción, la intriga, el fraude y la insolencia de los facciosos o de los aspirantes más descarados", lo que había dado lugar a que

el espíritu de partido, la venalidad y la ignorancia [hubieran] excluido de las elecciones activas y pasivas a los ciudadanos honrados, a casi todos los que podrían ejercer con utilidad pública los más importantes derechos públicos. ${ }^{31}$

La elite política criolla, compuesta por partidarios de las tendencias "liberal" y "conservadora", se oponía abiertamente al sufragio universal denunciando las consecuencias negativas que sobre la vida pública había traído la intervención política activa de las masas.

Tres décadas después de haber constatado la forma en que el pueblo era manipulado con fines políticos, así

30 "Memoria 1823", 1945, p. 73.

31 Mora, Obras, 1963, p. 723. 
como los fraudes, abusos y anarquía a que habían dado lugar las nuevas prácticas políticas, Alamán se declaraba en "contra de todo lo que se llama elección popular, mientras no descanse sobre otras bases" ${ }^{32}$ Asimismo, criticaba con dureza las transformaciones que había introducido la legislación liberal emanada de la Constitución de Cádiz. Refiriéndose a la situación de los indios, afirmaba que

en cambio del vano derecho que se les concedió, de ir a presentar a una mesa electoral un papel que se les daba escrito con los nombres de personas que ellos generalmente no conocían, ni sabían el objeto con que ello se hacía, quedaron privados de todas las ventajas muy positivas que les procuraban las leyes especiales de Indias. 33

Por su parte, José María Luis Mora negaba el ejercicio de la soberanía popular por considerar que "la miseria y las escaseces fomentan y son una tentación muy fuerte para todos los vicios antisociales, tales como el robo, la falta de fe en las estipulaciones y promesas y sobre todo la propensión a alterar el orden público ${ }^{34}$ Por ello proponía limitar el ejercicio de la participación política en toda la república mediante la exclusión del derecho de ciudadanía a "todos los que no pueden inspirar confianza ninguna, es decir, los no propietarios". 35

32 Alamán, "Carta", 1986, pp. 313-316.

33 A lamán, Historia, 1985, vol. 3, p. 126.

34 Mora, Obras, 1963, p. 634.

35 Cursivas nuestras. Más adelante, Mora especificaba que podian gozar de ese privilegio quienes "tengan una subsistencia independiente y desahogada", entre los que se encontraban "todas las profesiones [...], los dueños o usu-
Lucas Alamán propuso restringir el acceso a los sistemas electorales por medio de la representatividad territorial de los ayuntamientos y de la representación de los diversos sectores de notables, a través de los cuales quería garantizar la sabiduría del cuerpo legislativo. El decreto de convocatoria a la Asamblea que, de acuerdo con el Plan de San Luis, debía elegir al presidente y convocar al Congreso Constituyente en enero de 1846, muestra el modelo de representación estamental propuesto por Alamán, quien fuera el autor de gran parte del documento. En él se establecían las cuotas de representantes de los diferentes estamentos y corporaciones en la siguiente forma:

Propiedad rústica y urbana
e industria

$\begin{array}{ll}\text { Agrícola } & 38 \\ \text { Comercio } & 20 \\ \text { Mineria } & 14 \\ \text { Industria manufacturera } & 14 \\ \text { Profesiones literarias } & 14 \\ \text { Magistratura } & 10 \\ \text { Administración pública } & 10 \\ \text { Clero } & 20 \\ \text { Ejército } & 20\end{array}$

fructuarios de capitales o fincas, los empleados, los profesores de las artes o ciencias, los que tengan cualquier género de industria permitido por las leyes; si de su ocupación reportan la cuota de utilidades que se estime bastante ${ }^{n}$. Ibid., pp. 631, 635. 
El decreto exponía cómo "por primera vez $[. .$.$] todas las clases y profe-$ siones legítimas y verdaderamente representadas, [podrían] deliberar sobre los destinos del país"; 36 se pretendía asi que las leyes fueran elaboradas por di. putados conocedores de la materia sobre la que legislaban.

\section{CENTRALISMO Y ESTA BILIDAD POLITICA}

Según Lucas Alamán, solamente ungobierno nacional vigoroso podría unificar y organizar a los diversos poderes que coexistian en el país, por lo que fue partidario de mantener un régimen central sustentado en la representatividad de los ayuntamientos. La propuesta alamanista buscaba conservar "la forma de gobierno a que la nación estaba acostumbrada", por considerar que "era el resultado del saber y de la experiencia, y antes de llegar a los resultados que se habían obtenido, había sido menester pasar por largas y reiteradas pruebas". ${ }^{37}$ Pero, ante todo, pretendía neutralizar las tendencias autonomistas de los poderes territoriales que en su época amenazaban a la república con "una combustión general" capaz de conducirla "hasta el punto de perder la unidad nacional".

En el curso del siglo XVIII la paulatina disminución del aparato administrativo colonial fuera de la capital virreinal había fortalecido el poder local que ejercían de manera informal las

36 Citado en Reyes Heroles, Liberalismo, 1982, vol. II, p. 343.

${ }^{37}$ Alamán, Historia, 1985, vol. 1, p. 84 y vol. 5, p. 114.

38 "Memoria", 1945, p. 182 . oligarquías de provincia. ${ }^{39}$ Los reajustes producidos a raíz de la aplicación de las reformas borbónicas y del crecimiento económico de las últimas décadas de ese siglo condujeron a dichos grupos a intentar redefinir su relación con los poderes del centro. Aquellos que tenían mayor fuerza económica presionaron para conseguir la creación de tribunales mercantiles independientes del de la ciudad de México pero, debido a la oposición de éste, únicamente lo consiguieron Veracruz y Guadalajara, quedando pendientes las demandas de Puebla, Valladolid, Guanajuato, Querétaro, Orizaba y Oaxaca. ${ }^{40}$

La petición autonomista de 1808 , que propugnaba por la participación política de los cuerpos municipales, dio cauce a la búsqueda de reconocimiento institucional por parte de las oligarquías territoriales. ${ }^{41}$ Estas obtuvieron su primer éxito cuando en 1812 los representantes electos de los cabildos novohispanos ante las Cortes de Cádiz consiguieron la incorporación de las diputaciones provinciales a la Constitución. 42 Esta nueva institución, que gozaba de facultades administrativas, quedó directamente su-

39 Carmagnani, "Territorialidad", 1984, pp. 292-296.

40 Hamnet, "Factores", 1984, pp. 305-307 y "Mercantile", 1976, pp. 275.286.

41 Carmagnani, "Territorialidad", 1984, pp. $295,296$.

42 La creación de las diputaciones provinciales fue resultado de la propuesta de Miguel Ramos Arizpe, delegado de la provincia de Coahuila; éstas estaban formadas por siete miembros electos $\mathrm{y}$ presididas por un jefe político $\mathrm{y}$ un intendente designados por el rey. Benson, Diputación, 1955, pp. 11-15. 
bordinada al gobierno central de España e independiente del de la ciudad de México, el cual fue reducido a una diputación provincial más. Sin embargo, dicha reorganización fue suspendida en sus inicios por la restauración de Fernando VII, en mayo de 1814. ${ }^{43}$

Durante la guerra, el bloqueo de los caminos que conectaban a la ciudad de México con el interior y con los puertos de Veracruz y Acapulco, ${ }^{44} \mathrm{fa}$ voreció la independencia económica de algunas provincias por la intensificación del contrabando y la apertura de los puertos de San Blas y Tampico. ${ }^{45}$ Guadalajara y San Luis Potosí, por ejemplo, incrementaron notablemente su comercio directo con los extranjeros y ampliaron sus mercados regionales de modo que al decretarse el libre cambio, luego de la independencia, se transformaron en centros de redistribución de mercancías importadas en el norte del país. ${ }^{46}$

La oposición a Iturbide, quien además de sus ambiciones imperiales emprendió una lucha permanente contra el Congreso y quiso reforzar el centralismo, dio lugar a la alianza de las oligarquías de algunas provincias con caudillos militares como José Antonio Echávarri en Puebla, Luis Quintanar en Guadalajara y Antonio López de Santa Anna en Veracruz y San Luis Po-

43 Ibid., pp. 11.21.

44 Entonces, los únicos puertos autorizados para el comercio exterior.

45 A lamán, Historia, 1985, vol. 3, p. 343; Anna, Caída, 1981, pp. 168, 169; Ladd, Noble$z a, 1984$, pp. 171-173; Ward, México, 1981, p. 280.

46 "Memoria 1825", 1845, p. 154; Ortega y Medina, Zaguán, 1987, p. 48; Ward, México, 1981, p. 283. tosí.77 Dicha alianza originó el federa. lismo radical que surgió en 1823 con el Plan de Casa Mata, que encabezó las demandas promovidas por los comandantes de los estados que en las últimas décadas habían reafirmado con más fuerza sus intereses económicos. Jalisco fue el primero en proclamarse "Estado libre, independiente y soberano" reconociendo a la capital únicamente como "centro de unión" y abrogándose el derecho de determinar qué órdenes emanadas de los poderes centrales se aplicarían en el estado; además de negarse a reconocer "otras relaciones con los demás estados o provincias, que las de fraternidad y confederación ${ }^{n} .{ }^{48}$

Lucas Alamán, como secretario de Relaciones Exteriores e Interiores en el gobierno del supremo poder ejecutivo, ${ }^{49}$ se esforzó por reclamar la auto. ridad del gobierno central sobre las provincias con el apoyo de otros jefes militares como Nicolás Bravo, Miguel Negrete, Manuel Gómez Pedraza y Vi. cente Guerrero. En el Congreso, algunos liberales como Lorenzo de Zavala y José María Luis Mora se opusieron a un federalismo que les parecía peligro. samente exaltado. Mora se lamentó del ascendiente del "egoísmo provincial" al considerar que "las diputaciones se habían excedido en sus facultades [rompiendo] 'el vínculo que las une con las demás provincias' ".50

47 Hamnett, Factores, 1984, p. 310.

48 Muriá, Jalisco, 1987, pp. 439-440.

49 El Supremo Poder Ejecutivo estuvo integrado por Nicolás Bravo, Pedro Celestino Negrete y Mariano Michelena.

50 Hale, Liberalismo, 1982, p. 85. 
Fray Servando Teresa de Mier, luego de afirmar que el voto de la nación estaba por la república, agregaba:

Sólo nos diferenciamos en que algunos la quieren confederada, y yo con la mayoría la quiero central a lo menos durante 10 o 12 años, porque no hay en las provincias los elementos necesarios para ser cada una estado soberano, y todo se volvería disputas y divisiones. ${ }^{51}$

Poco después, ante el incontenible avance del federalismo radical, preveía la amenaza de la reconquista española apoyada por la Santa A lianza, por lo que se opuso al autonomismo de estados "soberanos" que podria "enervar la acción del gobierno" y "destruir la unidad que se tenía". 52

Con la Constitución de 1824 se estableció un federalismo en el que las diputaciones provinciales -vigentes por la adopción de la Constitución liberal española en el Plan de Iguala- se transformaron en los nuevos estados, cuya soberanía en materia de gobierno y administración les posibilitó asumir la mayor parte de las atribuciones que hasta entonces había detentado el gobierno central. 53

La mayoria federalista del segundo Congreso Constituyente reorganizó el sistema fiscal dividiendo los impuestos nacionales en federales y estatales, a fin de fortalecer las autonomías de los estados. ${ }^{54}$ Con ello disminuyeron

51 Mier, Servando, 1977, p. 97.

52 Ibid., pp. 290-292. p. 66

53 Véase mapa en Benson, Diputación, 1955 ,

54 El primero mantuvo los derechos aduaneros, los monopolios, los bienes nacionales y las los ingresos de la federación en $46 \%$ aproximadamente, por lo que los estados se comprometieron a compensar el desequilibrio enviando una asignación mensual denominada "contingente", la cual formalizaba la pretendida supremacía del poder central. Tal división profundizó la autonomía estatal, pues la mayoría de las provincias enviaron sólo una parte mínima del "contingente", la cual se redujo en forma progresiva. 55

La historiografia contemporánea ha encontrado tras este hecho la "clara intención [de las oligarquías territoriales] de impedir el funcionamiento del poder central, bloqueando por consiguiente el inicio de una nueva dinámica estatal". ${ }^{56}$ Según Lucas Alamán, los problemas confrontados por el gobierno federal a raíz del establecimiento de la Constitución de 1824, derivaban de la supremacía concedida por dichas leyes fundamentales al poder legislativo, cuya fuerza, unida a la otorgada por el régimen federal a las legislaturas de los estados, permitía que éstas operaran como verdaderas "corporaciones oligárquicas". Por ello reivindicaba el establecimiento de

la república central, con cierta amplitud de facultades en las provincias, divididas éstas en territorios más pequeños, para poder hacer el bien local sin

rentas de los territorios, en tanto que los estados se apropiaron de todos los impuestos exigibles en su territorio.

55 Carmagnani, "Finanzas", 1983, pp. 286, 287; Macune, Estado, 1984, pp. 7.98; Tenenbaum, "Centralista", pp. 6, 7 .

56 Carmagnani, "Finanzas", 1983, p. 287. 
los inconvenientes que producen las so. beranías de los Estados, 57

a los que únicamente se les conferirian facultades en materia administrativa.

\section{ADMINISTR ACIÓN Y CORPORATIVISMO}

Lucas Alamán ha sido atacado por haber estado a favor de la permanencia de las instituciones de carácter corporativo identificadas con el régimen colonial, como el ayuntamiento, la Iglesia y el ejército. Detengámonos a analizar el porqué del apoyo de Alamán a la primera de estas instituciones, cuya vigencia para nuestro país ha sido demostrada con su incorporación a la Constitución de 1917 como resultado de la lucha que libraron los pueblos por reivindicar su permanencia. ${ }^{58}$ Alamán fue decidido partidario del municipio por considerarlo la institución representativa de mayor tradición en México y el sustento de la representatividad política de la nueva república. ${ }^{59}$ En ello coincidía José Ma-

57 Citado en Reyes Heroles, Liberalismo, 1982, vol. II, p. 158.

58 Al respecto, pueden consultarse entre otros a Fraser, "Política", 1972, pp. 615-651; Knight, "Liberalismo", 1985, pp. 59-91; Knowlton, "Individualización", 1978, pp. 24-61; Powel, Liberalismo, 1974 y "Liberales", 1972, pp. 653-675.

59 Cuando fue electo presidente municipal del ayuntamiento de la ciudad de México en 1849, Alamán exponia: "Fueron los cuerpos mu. nicipales, en su origen, el principio y la base de la libertad civil: los fueros o cartas de privilegios de las ciudades y villas, eran una parte esencial de las instituciones nacionales, y la observancia de estos fueros, fue por mucho tiempo la seguridad que tuvieron las personas y las propiedades. Las ría Luis Mora, quien afirmó que llega. ría un momento en que los municipios "serían los móviles primeros de la prosperidad pública". 60

La legislación real castellana había concedido a los cuerpos municipales autonomía gubernamental, administrativa y judicial. En materia económica los ha: bía dotado del derecho a disponer de bienes rústicos y urbanos, conocidos con el nombre de "propios", con cuyas rentas financiaban los servicios públicos, pudiendo también recurrir, con autorización del virrey, a la imposición de contribuciones especiales llamadas "arbitrios" cuando los productos de los "propios" eran insuficientes. Ello les había permitido mantenerse como una de las instituciones más sólidas y mejor or ganizadas hasta fines de la colonia, ${ }^{61}$ a pesar de la tendencia de los terratenientes a expandir sus propiedades a costa de las de los pueblos vecinos reduciéndolos a los peores terrenos, lo que en algunos casos había provocado su desaparición. ${ }^{62}$

El proceso de desposesión de las tierras de los pueblos se incrementó en las últimas décadas del siglo XVIII, a raíz del fortalecimiento de los intere. ses agrarios de las oligarquías territoriales debido a la apertura comercial iniciada en 1760.63 Ello sin que la corona y su burocracia pudieran contener tales usurpaciones debido al gran poder detentado por dichas oligarquías.

facultades de estos cuerpos eran grandes, y grande también fue el beneficio que con ellas hicieron." Valadés, Alamán, 1987, p. 453.

60 Hale, Liberalismo, 1982, p. 91.

61 Guerra, México, 1988, pp. 250-257.

62 Miranda, "Propiedad", 1966, pp. 168181.

63 Meyer, Esperando, 1984, pp. 66, 67. 
A este problema se aunó la pérdida de la autonomía financiera de los municipios por el traspaso de la administración de los "propios" y "arbitrios" a un funcionario virreinal, medida introducida en 1767 por los reformistas Borbones con el fin de racionalizar los gastos de los municipios y proporcionar mayores recursos a la Real Hacienda. ${ }^{64}$

En la época de Alamán los municipios se encontraban en plena decadencia como resultado de las reformas liberales del constitucionalismo gaditano que, aunque formalmente les restituyó la administración de los "propios" y "arbitrios", transformó los cuerpos municipales en meras divisiones administrativas y suprimió su competencia jurídica y de gobierno. Según José María Luis Mora el deterioro de los ayun. tamientos se había originado a raíz del establecimiento de las diputaciones provinciales "cuando, por falta de una autoridad central, enseñoreó el 'espíritu del desorden' " .65

Como vimos anteriormente, la elección de los consejos municipales de acuerdo con la Constitución de Cádiz, "a pluralidad de votos con proporción a su vecindario", ${ }^{66}$ permitió la intromisión de agentes extraños en el gobierno de los pueblos, hecho que fue denunciado por Lucas A lamán en $1823 .{ }^{67}$ Ante este problema, los diputados del estado de México, Manuel de Villaverde y José María Jáuregui, pensaban que sólo mediante el control estricto de los municipios por prefectos nom-

64 Guerra, México, 1988, p. 230.

65 Hale, Ltberalismo, 1982, p. 90.

66 Constituctón, s.a., pp. 37, 38.

67 “Memoria 1823", 1945, p. 73. brados por el gobierno del estado se podría poner freno a la manipulación de las oligarquías locales. ${ }^{68}$

Alamán puso especial empeñoen impulsar los municipios. Desde el Ministerio de Relaciones fomentó su establecimiento instruyendo a los pueblos sobre los requisitos necesarios para su erección y, siempre que ocupó cargos públicos, se esforzó por evitar que las funciones municipales se restringieran a la esfera política apoyando sus atribuciones de carácter administrativo. ${ }^{69}$ En este aspecto, Mora coincidió plenamente con Alamán al opinar que sólo una mayor responsabilidad en el ámbito administrativo remediaría la situación de los municipios. ${ }^{70}$

El interés de Alamán por que los ayuntamientos cumplieran con sus múltiples funciones -justicia, policía, educación, asistencia social y obras públicas- lo condujo a reclamar la administración de los "propios" y "arbitrios" por parte de los municipios. Asimismo, demandó claridad de cuentas a los subdelegados y jueces de letras, en quienes había caído el manejo de los bienes de comunidad a raíz de la restauración de las reformas administrativas introducidas por los Borbones a fines del siglo XVIII. ${ }^{71}$

En la época de Alamán se volvió a abrir el debate, iniciado por los reformadores Borbones, entre la tendencia que proponía mantener la propiedad comunal como base material de los municipios y la que pugnaba por su

68 Hale, Liberalismo, 1982, p. 91

69 "Memoria 1823", 1945, pp. 72, 76.78; Guerra, Mexico, vol. I, pp. 251.257.

70 Hale, Liberalismo, 1982, p. 92.

71 "Memoria 1823 ", 1845, pp. $77,78$. 
distribución entre los habitantes de los pueblos en su calidad de individuos. Esta última partía del supuesto de que liberados de las restricciones y fidelidad que debían a la Iglesia y a las comu. nidades, podrían velar por sus propios intereses. ${ }^{72}$ Lucas Alamán presentó a Ia diputación provincial de México un plan en el que propuso "la distribución de los ejidos y tierras de comunidad a los vecinos de los pueblos, bajo un censo moderado", y el establecimiento de varios "arbitrios" a fin de que los ayuntamientos pudieran disponer de ingresos para la satisfacción de sus gastos públicos. ${ }^{73}$

Respecto de la discusión sobre el grado de libertad administrativa que debía concederse a los ayuntamientos, Alamán, consciente de que el manejo de los fondos públicos requería de "conocimientos peculiares de dedicación $y$ uniformidad, $y$ [que] ninguna de estas cualidades puede esperarse de corporaciones electivas popularmente y frecuentemente renovadas", propuso se remunerara a los individuos encargados de la recaudación e inversión de los ingresos municipales. Con esta medida pretendía dotar a dichas corporaciones de administradores capaces, dedicados exclusivamente a su trabajo y sujetos a la inspección del ayuntamiento electivo, con lo que se reduciría "el peligro de la mala versación" ${ }^{74}$

Mientras ocupó cargos públicos, Lucas Alamán insistió en que los pueblos pudieran disponer con libertad

72 Brading, Orígenes, 1980; p. 105; Hale, $L t$ beralismo, 1982, p. 190.

73 "Memoria 1823 ", 1845, vol. 1, p. 78.

74 "Memoria 1831", 1845, pp. 295, 296. de sus "propios" y en que se dotara de fondos particulares a los municipios para la subvención de sus gastos. A partir del ascenso del federalismo puso mayor énfasis en este aspecto, ya que, como vimos, el nuevo sistema de gobierno condujo a la sustracción de los ingresos municipales por parte de los estados. ${ }^{75}$

\section{ConClusiones}

Para Lucas Alamán el problema fundamental del país en su época era el mantenimiento de la unidad y la estabilidad politica, condiciones indispensables para la soberanía y el crecimiento económico. De aquí que se preocupara por establecer bases precisas para la participación política, la representación del ayuntamiento y la construcción de un poder central sólido que llenara el vacío que dejó la crisis virreinal.

El dilema entre monarquía constitucionalista o república resume el drama de una elite dirigente dividida. Comerciantes, propietarios, mineros, militares y clérigos impusieron al territorio novohispano una nueva división político-administrativa, y sus enfrentamien. tos ideológico-políticos dieron lugar al caos militarista que privó en el país durante las décadas que siguieron a la consumación de la independencia.

El monarquismo constitucional y la posición centralista de Lucas Alamán deben entenderse en el contexto de su época y de la generación de criollos que ingresó en la arena política con el constitucionalismo de 1812 y 1820.

75 "Memoria 1830", 1945, pp. 214-218; "Memoria 1831", p. 316; Alamán, Documentos, 1945 , vol. 3 , p. 386. 


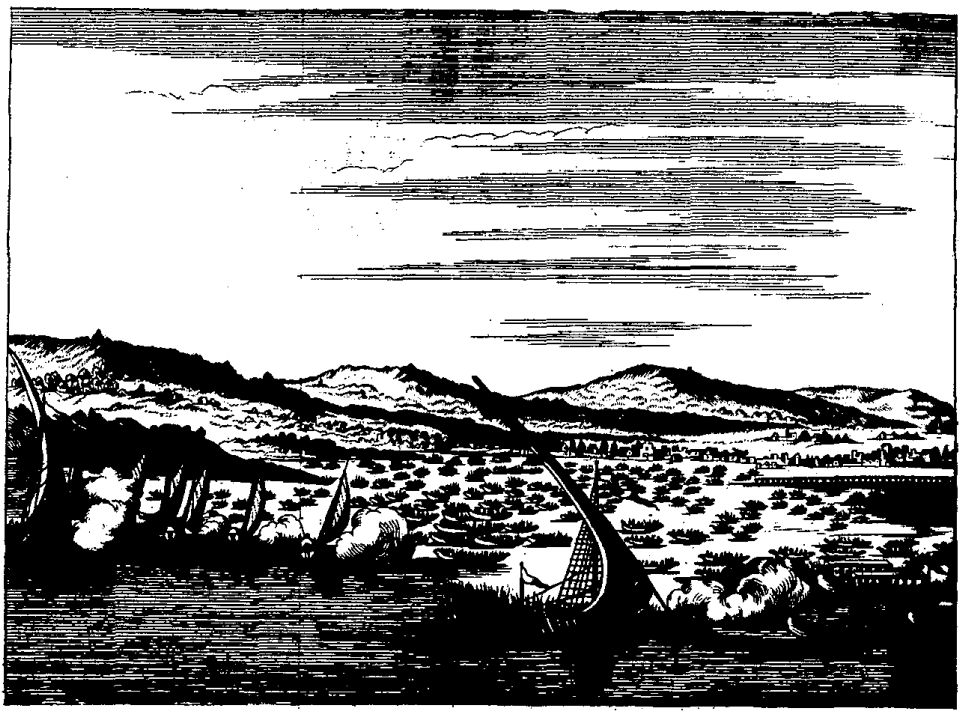

Alamán formó parte del autonomismo constitucional novohispano y de la elite dirigente independentista que, enfrascada en una intensa lucha de facciones, tuvo que afrontar el problema de carecer de legitimidad política para establecer la gobernabilidad indispen. sable que reencauzara el crecimiento económico perdido al finalizar el periodo colonial.

Junto con lo anterior, la pérdida de grandes extensiones del territorio a consecuencia de la invasión norteamericana de 1846-1848 produjo el desaliento y la desesperación que sufrió la generación de políticos que desde la proclamación de la independencia se había esforzado por darle coherencia y destino a la joven nación. Por ello, Lucas Alamán pugnó por fincar las bases del Estado nacional sustentándolo en un poder central fuerte y en 1849, como reacción inmediata a la crisis de Estado que dejó la mutilación física del país, se autoproclamó conservador.

Durante los años 1849.1853 reinaba en el país un ambiente de confusión política y social que desembocó en una profunda crisis. Para afrontarla los liberales y los conservadores, encabezados por Lucas Alamán, recurrieron nuevamente a Antonio López de Santa Anna quien, por onceava y última vez, prestamente reasumió el poder.

\section{BIBI.IOGR AFÍA}

-Abad y Queipo, Manuel, "Edicto importante, dirigido a evitar la nueva anarquía 
que nos amenaza si no se dividen con equidad entre deudores y acreedores los daños causados por la insurrección, y no se pone modo y término en las ejecuciones", en Crédito Público. Escritos del Obispo Abad $y$ Queipo [...] presentados y recopilados por José María Luis Mora, Coordinación de Humanidades/Miguel ÁngelPorrúa, México, 1986 (Biblioteca Mexicana de Escritores Políticos).

-Alamán, Lucas, Historia de Méjico desde los primeros movimientos que prepararon su independencia en el año de 1808 hasta la época presente; Instituto Cultural Helénico/Fondo de Cultura Económica, México, 1985,5 vols.

Carta de Lucas Alamán a Santa Anna", en Gastón Garcia Cantú, Antología. El pensamiento de la reacción mexicana (1810-1859), UNAM, México, 1986, tomo I (Lecturas Universitarias, 33).

, Documentos diversos (iné. ditos y muy raros), Editorial Jus, México, 1945, 3 vols. (Colección de Grandes Autores Mexicanos, 9).

-Anna, Timothy, La caída del gobier. no español en la ciudad de México, Fondo de Cultura Económica, México, 1981.

-Annino, Antonio, "El pacto y la norma. Los orígenes de la legalidad oligárquica en México", en Historias, núm. 5, enero. marzo 1984.

-Arias, Juan de Dios, México a través de los siglos, obra coordinada por Vicente Riva Palacio, Editorial Cumbre, México, 1987, tomo XI.

-Arrom, Silvia M., "Popular Politics in Mexico City: The Parian Riot, 1828", The Hispanic American Historical Review, vol. 68, núm. 2, mayo 1988.

-Benson, Nettie Lee, La diputación provincial y el federalismo mexicano, El Colegio de México, México, 1955.

-Brading, David, Los orígenes del nacionalismo mexicano, Era, México, 1980.

-Carmagnani, Marcello, "Territorialidad y federalismo en la formación del Estado mexicano", en Jorge Buisson et al., Pro- blemas de la formación del Estado y la nación en Hispanoamérica, Bohlaw Verlag, Colonia y Viena, 1984.

, "Finanzas y Estado en México, 1820-1880" en Ibero Amerikanisches Archiv, vol. 9, núm. 3-4, 1983.

-La conciencia nacional y su formación. Discursos cívicos septembrinos (1825-1871), compilación y prólogo de Ernesto de la Torre Villar, UNAM-Coordinación de Humanidades, México, 1988.

-Constitución de Cádiz, 1812, PRI/Comisión Nacional Editorial, México, s.a.

-Fraser, Donald, "La política de desamortización en las comunidades indigenas, 1856-1872", en Historia Mexicana, vol. $\mathrm{xXI}$, núm. 4(84), abril-junio 1972.

-Guerra, François-Xavier, México: del Antiguo Régimen a la Revolución, Fondo de Cultura Económica, México, 1988.

-Hale, Charles A., El liberalismo mexicano en la época de Mora, 1821-1853, Siglo XXI Editores, México, 1982.

-Hamnett, Brian, "Factores regionales en la desintegración del régimen colonial de la Nueva España: el federalismo de 1823. $1824^{\prime \prime}$, en Jorge Buisson et al., Problemas de la formación del Estado y la nación en Hispanoamérica, Bohlan Verlag, Colonia y Viena, 1984.

"Mercantile rivalry and peninsular division: the consulado of New Spain and the impact of the Bourbon reforms, 1789-1824", Ibero-Amerikanisches Archiv, N.F., vol. 2, nüm. 4, 1976.

-Jáuregui, José María, Discurso en que se manifiesta que deben bajarse los réditos a proporción del quebranto que hayan sufrido en la insurrección los bienes $y$ giros de los deudores, Impreso en la Ofi. cina de D. Alejandro Valdés, México, 1870.

-Knight, Alan, "El liberalismo mexicano desde la Reforma hasta la revolución (una interpretación)", Historia Mexicana, vol. XXXV, núm. 1(137), julio-septiembre 1985 .

-Knowlton, Robert, "La individualización de la propiedad corporativa civil en el 
siglo XIx. Notas sobre Jalisco", Historia Mexicana, vol. XXvIr, núm. 1 (109), julio-septiembre 1978.

-Ladd, Doris M., La nobleza mexicana en la época de la independencia, 17801826, Fondo de Cultura Económica, México, 1984.

-Macune, Charles W. Jr., El Estado de México y la federación mexicana, 1821 1835, Fondo de Cultura Económica, Méxi$\mathrm{co}, 1984$.

-"Memoria que el secretario de Estado y del Despacho de Relaciones Exteriores e Interiores presenta al Soberano Congreso Constituyente sobre los negocios de la Secretaría de su cargo, leída en la sesión de 8 de noviembre de 1823", en Lucas Alamán, Documentos diversos (inéditos y muy ra. nos), Editorial Jus, México, 1945, vol. 1 (Colección de Grandes Autores Mexicanos, 9).

- Memoria de la Secretaría de Estado y del Despacho de Relaciones Exteriores e Interiores leída por el secretario del ramo en la Cámara de Diputados el día 12 de febrero de 1830, y en la de Senadores el día 13 del mismo", en Lucas Alamán, Documentos diversos (inéditos y muy raros), Editorial Jus, México, 1945, vol. 1 (Colección de Grandes Autores Mexicanos, 9).

- Memoria presentada a las dos Cámaras del Congreso General de la Federación por el secretario de Estado y del Despacho de Relaciones Exteriores e Interiores al abrirse las sesiones del año de 1825 , sobre el estado de los negocios de su ramo", en Lucas Alamán, Documentos diversos (inéditos y muy raros), Editorial Jus, México, vol. 1 (Colección de Grandes Autores Mexieanes, 9).

-"Memoria de la Secretaría de Estado y del Despacho de Relaciones Exteriores e Interiores. Presentada por el secretario del ramo a las Cámaras del Congreso general, en cumplimiento del artículo 120 de la Constitución, y leída en la de Diputados el día 7, y en la de Senadores el 8 de enero de 1831 ", en Lucas Alamán, Documentos di- versos (inéditos y muy raros), Editorial Jus, México, 1945, vol. 1 (Colección de Grandes Autores Mexicanos, 9).

-Meyer,Jean, Esperando a Lozada, ElCokegio de Michoacán/Conacyt, México, 1984.

-Mier, Fray Servando Teresa de, Historia de la Revolución de Nueva España, antiguamente llamada Anáhuac o verdadero origen y causas de ella con la relación de sus progresos hasta el presente año de 1813, Instituto Cultural Helénico/Fondo de Cultura Económica, México, 1986,2 vols.

, Fray Servando. Biografia / discursos / cartas, México, Gobierno y Universidad de Nuevo León, Dirección General de Investigaciones Humanísticas, 1977.

, Profecía Política del sabio doctor D. Servando Teresa de Mier, diputado por Nuevo León y con respecto a la Federación Mexicana, Tipografia de Rafael, México, 1849.

-Miranda, José, "La propiedad comunal de la tierra y la cohesión social de los pueblos indígenas mexicanos", Cuadernos Americanos, vol. CxıIX, núm. 6, noviembre-diciembre 1966.

-Mora, José María Luis, México y sus revoluciones, Editorial Porrúa, México, 1977, tomo In (Colección de Escritores Mexicanos).

rrúa, México, 1963.

-Muriá, José María et al. (comps.), Jalisco en la conciencia nacional, Gobierno del Estado de Jalisco/Instituto de Investigaciones Dr. José María Luis Mora, México, 1987,2 vols.

-Ortega y Medina, Juan, Zaguán abierto al México republicano (1820-1830), UNAM, México, 1987.

- "Plan de la independencia de la América septentrional", en Berta Ulloa/Joel Hernández Santiago (coords), Planes en la nación mexicana, Senado de la República/El Colegio de México, México, 1987. Libro 1. 
-"Plan de Paz y plan de guerra del Sr. José María Cos, 1812", en Berta Ulloa/Joel Hernández Santiago, Planes en la nación mexicana, Senado de la República/El Colegio de México, México, 1987, Libro 1.

-Powel, T. G., El liberalismo y el campesinado en el centro de México, Secretaría de Educación Pública, México, 1974 (Sepsetentas, 122).

$$
\text { , "Los liberales, el campesina- }
$$

do indigena y los problemas agrarios du. rante la Reforma", Historia Mexicana, vol. XXI, núm. 4, abril-junio 1972.

-Quirós, José María, "Memoria de estatuto. Idea de la riqueza que daban a la masa circulante de Nueva España sus naturales producciones en los años de tranquilidad, y su abatimiento en las presentes conmo. ciones", en Luis Châvez Orozco (comp.), La libertad de comercio en la Nueva España en la segunda década del siglo XTX, Secretaría de Hacienda y Crédito Público. Dirección de Estudios Financieros, México, 1943 (Archivo Histórico de Hacienda. Colección de documentos publicados bajo la dirección de Jesús Silva Herzog).
-Reyes Heroles, Jesús, El liberalismo mexicano, Fondo de Cultura Económica, México, 1982, 3 vols.

-Schneider, Jürgen, Minería, acuñaciones y comercio exterior de México en la época de la emancipación (1821. 1850), Eihelm Fink Verlag, Munich, 1980.

-Tenenbaum, Barbara A., "The centralista conundrum in the nineteenth century Mexico" (mimeografiado).

-Valadés, José, Alamán: estadista e historiador, Universidad Nacional Autónoma de México, México, 1987.

-Villoro, Luis, "La revolución de Independencia", en Historia general de México, El Colegio de México, México, 1981, vol. 1.

- Ward, Henry George, México en 1827, México, Fondo de Cultura Económica, 1981 (Biblioteca Americana).

-Zavala, Lorenzo de, Ensayo histórico de las revoluciones de México desde 1808 hasta 1830, Instituto Cultural Helénico/Fondo de Cultura Económica, México, 1985. 